\title{
Leitura e Escrita: trabalhando com projetos no Ensino Fundamental
}

\author{
Recebido em 29.04.2015. Aprovado em 05.05. 2015
} Avaliado pelo sistema double blind review

\author{
Marly Neves \\ eegabrielamistral2012@gmail.com \\ Escola Estadual GABRIELA MISTRAL - São Paulo -SP - Brasil
}

\section{Resumo}

O programa Educação - Compromisso de São Paulo, iniciado em 2011, estabelece um pacto com a sociedade em prol da educação. Entre suas principais metas, o programa pretende fazer com que a rede estadual paulista figure entre os 25 melhores sistemas de educação do mundo nas medições internacionais, além de posicionar a carreira de professor entre as dez mais desejadas do Estado.

O programa está estruturado em cinco pilares, que nortearam o foco de atuação, o segundo pilar trata do aprimoramento da gestão pedagógica da rede com foco nos alunos. Dentro dessa estratégia, programas com bons resultados, como o Ler e Escrever, foram mantidos ou ampliados. Em uma ação pioneira, São Paulo ganhou uma nova meta de alfabetização, que estabelece que os estudantes saibam ler e escrever já aos 7 anos.

Tendo como eixo norteador a meta de alfabetização, a implementação do projeto proporcionará melhoria na aprendizagem dos alunos e aperfeiçoamento do trabalho do professor com alfabetização.

Para a realização deste empreendimento, o valor solicitado ao edital será de $R \$ 20.413,27$, destinados às despesas correntes, material de consumo e treinamento.

Este empreendimento vem ao encontro do Programa - Compromisso de São Paulo, e possibilitará melhoria na qualidade de ensino.

Palavras-chaves: Educação. Alfabetização. Plano de empreendimento. Leitura e escrita. 


\section{Contexto da escola}

\section{Identificação da Unidade Escolar}

A Escola Estadual GABRIELA MISTRAL está localizada na zona norte da capital, à Rua Major Baracca, $n^{0}$ 584 - Parque Edu Chaves - CEP: 02232-000 - São Paulo - SP, Telefones: (11) 2240-1033 - Fax: (11) 22434730, E-mail: e001089a@see.sp.gov.br / eegabrielamistral2012@gmail.com, sob a jurisdição da Diretoria de Ensino Região Norte 2 da Secretaria de Estado da Educação.

Ato de criação: Decreto n 27.331 - publicado em 12/02/1956 sob a denominação de Grupo Escolar do Parque Edu Chaves.

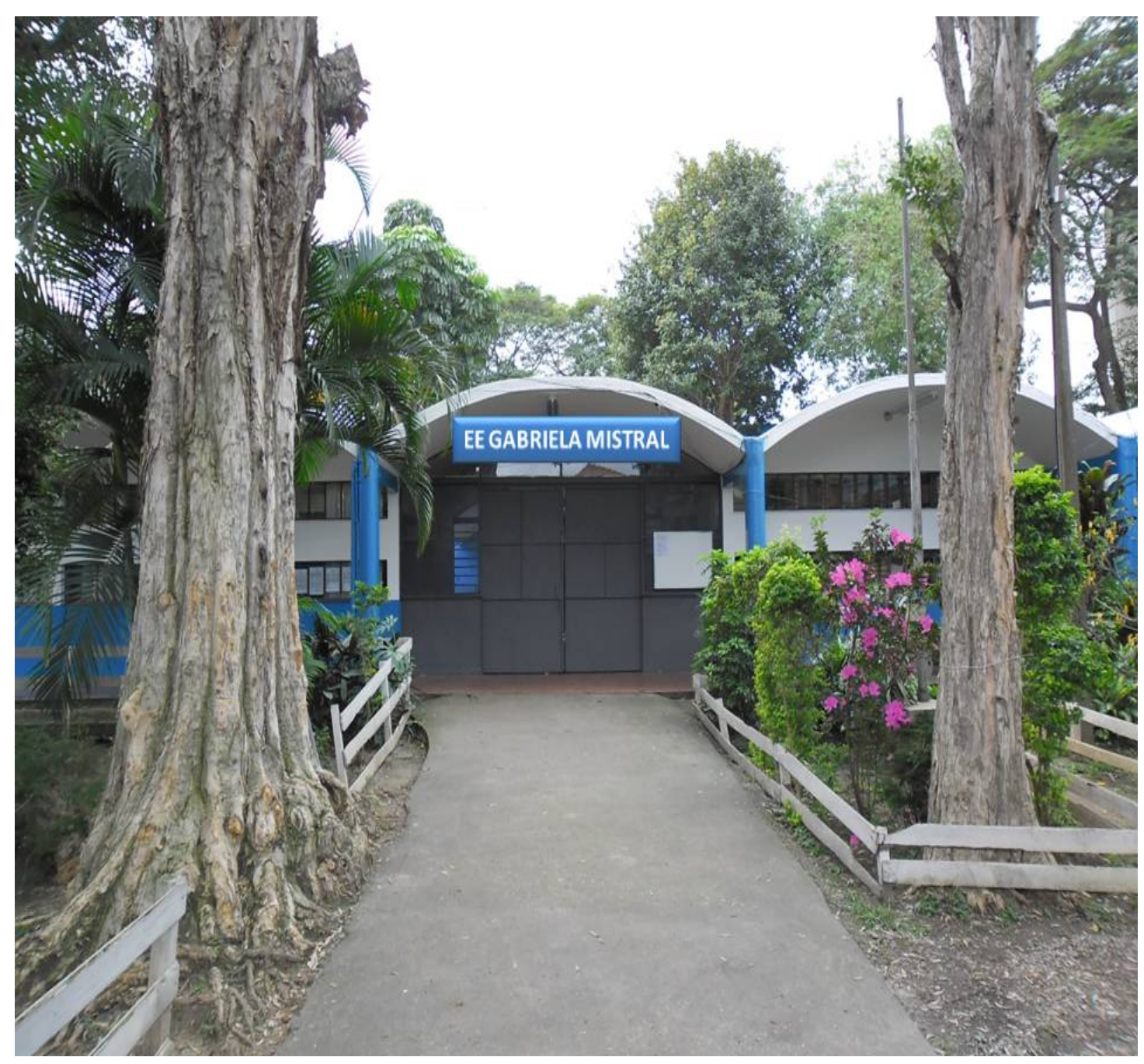

\section{Organização da Escola}

Cursos, modalidade e turnos de funcionamento oferecidos pela Unidade Escolar à comunidade:

\begin{tabular}{|l|l|l|l|l|l|}
\hline Cursos & $\begin{array}{l}\text { Modalidade/ } \\
\text { Nivel }\end{array}$ & Turno & $\begin{array}{l}\text { Perído } \\
\text { Funcionamento }\end{array}$ & Organização & $\begin{array}{l}\text { No }^{0} \text { de } \\
\text { alunos }\end{array}$ \\
\hline EF Ciclo I & $1^{\circ}$ ao $5^{\circ}$ ano & Tarde & $13 \mathrm{~h} 00$ às $17 \mathrm{~h} 30$ & Anual/200 dias & 231 \\
\hline EF Ciclo II & $6^{0}$ ao $9^{\circ}$ ano & Manhã & $07 \mathrm{~h} 00$ às $12 \mathrm{~h} 20$ & Anual/200 dias & 281 \\
\hline EJA EM & $1^{\circ}$ ao $3^{\circ}$ Termo & Noite & $19 \mathrm{~h} 00$ às $23 \mathrm{~h} 00$ & Semestral/100 & 127 \\
\hline
\end{tabular}


Missão: Contribuir para a formação, crescimento intelectual e inclusão social dos jovens e adultos da comunidade e entorno.

Como parte integrante da comunidade, é essencial que a escola compreenda o contexto social na qual está inserida, respeitando e valorizando suas necessidades, potencialidades e expectativas, sem direcionar suas atividades educativas apenas como expressão de um processo burocrático, e sim voltada para um atendimento educacional com o objetivo de formar cidadãos com capacidade de fazer escolhas com discernimento, senso crítico e autonomia.

\section{Caracterização da Unidade Escolar}

O Parque Edu Chaves é um bairro da Cidade de São Paulo. Situa-se à margem do Rio Cabuçu de Cima, da Rodovia Fernão Dias e faz divisa ao norte com o bairro Jaçanã, ao sul com a Vila Sabrina, a leste com 0 Jardim Brasil.

O bairro historicamente era formado por famílias de militares e ex-militares, motivo pelo qual, a maior parte de suas ruas tem o nome de muitos Capitães, Majores e Tenentes, em homenagem a esses que já se foram, porém contribuíram de alguma forma em prol do bairro.

O Grupo Escolar do Parque Edu Chaves fundado em 1956, hoje denominado E.E. GABRIELA MISTRAL, recebeu este nome em homenagem à poetisa chilena Lucila Maria Del Perpetuo Socorro Alcayaga,

nascida em Vicunã, uma vila situada no norte do Chile, em 7 de abril de 1889, faleceu em Nova lorque em 10 de janeiro de 1957; foi poetisa, educadora, diplomata e feminista chilena, agraciada com o Nobel de Literatura em 1945.

Hoje, os alunos da E.E.Gabriela Mistral são, em sua maioria, oriundos do Conjunto Residencial Cingapura (Programa PROVER - Programa de Verticalização de Favelas do município de São Paulo), que devido a sua proximidade com a Rodovia Fernão Dias e o Terminal de Cargas do Parque Novo Mundo, tornou-se um local de grande vulnerabilidade social.

Visão: Direcionamento de ações para a socialização do saber sistematizado, historicamente acumulado, como patrimônio universal da humanidade, fazendo com que este saber seja criticamente apropriado pelos estudantes, que já trazem consigo o saber popular, o saber da comunidade em que vivem e atuam. A interligação e a apropriação desses saberes pelos estudantes e pela comunidade local representam, certamente, um elemento decisivo para o processo de democratização da própria escola.

\section{Identificação do problema}

Todas as escolas, com Ciclo I, da Diretoria Norte 2 estão inseridas no Projeto Ler e Escrever da Secretaria da Educação do Estado de São Paulo. Mais do que um programa de formação, o Ler e Escrever é um conjunto de linhas de ação articuladas que inclui formação, acompanhamento, elaboração e distribuição de materiais pedagógicos e outros subsídios, constituindo-se dessa forma como uma política pública para o Ciclo I, que 
busca promover a melhoria do ensino em toda a rede estadual.

Os principais objetivos do Ler e Escrever são:

Apoiar o Professor Coordenador em seu papel de formador de professores dentro da escola;

Apoiar os professores regentes na complexa ação pedagógica de garantir aprendizagem de leitura e escrita a todos os alunos, até o final da $2^{\mathrm{a}}$ série do Ciclo I / EF;

Criar condições institucionais adequadas para mudanças em sala de aula, recuperando a dimensão pedagógica da gestão;

Comprometer as Universidades com o ensino público.

Possibilitar a futuros profissionais da Educação (estudantes de cursos de Pedagogia e Letras), experiências e conhecimentos necessários sobre a natureza da função docente, no processo de alfabetização de alunos do Ciclo I / EF.

O Ler e Escrever1 envolve a estrutura da SEE (CENP, COGSP, CEI e as Diretorias de Ensino) e promove tanto a participação dos gestores (Supervisores, Professores Coordenadores das Oficinas Pedagógicas PCOPs e Diretores de escolas), promovendo discussão de conteúdos que ampliem as possibilidades de compreensão, apoio, acompanhamento e avaliação para a tomada de decisões voltadas à aprendizagem dos alunos; quanto a formação pedagógica (para PCOPs e Professores Coordenadores - PCs), visando aperfeiçoar a didática de alfabetização e a formação de professores nas escolas.

Nesta linha de pensamento, o presente Plano de Empreendimento tem como objetivo criar condições para 0 desenvolvimento de projetos de alfabetização com a criação materiais pedagógicos de fácil manipulação, com baixo custo e que possibilite ao aluno uma aprendizagem significativa, com responsabilidade, eficiente e prazerosa.

O trabalho com projetos como ferramenta, é capaz de articular os propósitos didáticos com os comunicativos, permitem uma articulação dos saberes sociais e os escolares; estimulam a aprendizagem; favorecem a autonomia, pois envolve toda classe, e evitam o parcelamento do tempo e do saber, já que tem uma abordagem multidisciplinar. Nessa perspectiva o trabalho com projetos possibilita que os alunos discutam suas opiniões, busquem informações que possam auxiliá-los e procuram diferentes soluções, fatores importantes na formação de cidadãos praticantes da cultura escrita.

É fundamental que, no processo de alfabetização, as crianças saibam as funções sociais e as finalidades da leitura e da escrita; para que se aprende e escrever e a ler. Na fase de alfabetização, a criança necessita de apoio, auxílio e orientação de um adulto para aprender. Percebe-se então, a necessidade de o professor conhecer a realidade social e cultural do aluno, a fim de contribuir para a alfabetização significativa.

Analisando o Mapa da Escola com os resultados da sondagem ( $1^{\circ}$ e $2^{\circ}$ anos) e diagnósticos $\left(3^{\circ} 4^{\circ}\right.$ e $5^{\circ}$ anos), embora existam 70 (setenta) alunos alfabéticos, ainda temos 32 (trinta e dois) alunos silábico com valor e 21 (vinte e um) alunos silábicos-alfabéticos nas turmas de $1^{\circ}$ e $2^{\circ}$ anos, enquanto que nos $3^{\circ}, 4^{\circ}$ e $5^{\circ}$ anos apenas 36 (trinta e seis) alunos estão no nível Razoável e 38 (trinta e oito) alunos no nível Bom. Uma reflexão sobre os resultados apresentados se faz necessária.

\begin{tabular}{|l|l|}
\hline MAPA DA ESCOLA \\
DIRETORIA DE ENSINO REGIÃO NORTE 2 \\
ESCOLA: EE GABRIELA MISTRAL & \\
\hline
\end{tabular}

\footnotetext{
${ }^{1}$ WWW.educacao.sp.gov.br/projetos - 30/05/2014.
} 


\section{Marly Neves}

\begin{tabular}{|c|c|c|c|c|c|c|c|}
\hline DATA: 30 & IO/2014 & & & & & & \\
\hline Classes & $\begin{array}{l}\mathrm{N}^{0} \text { de } \\
\text { alunos }\end{array}$ & Pré-silábica & $\begin{array}{l}\text { Silábica sem } \\
\text { valor }\end{array}$ & $\begin{array}{l}\text { Silábica com } \\
\text { valor }\end{array}$ & $\begin{array}{l}\text { Silábica- } \\
\text { alfabética }\end{array}$ & Alfabética & $\begin{array}{l}\text { Total de } \\
\text { alunos }\end{array}$ \\
\hline $1^{\circ}$ anos & 52 & - & 1 & 25 & 9 & 17 & 52 \\
\hline $2^{\circ}$ anos & 73 & - & 1 & 7 & 12 & 53 & 73 \\
\hline TOTAL & 125 & - & 2 & 32 & 21 & 70 & 125 \\
\hline Classes & $\begin{array}{l}\mathrm{N}^{0} \mathrm{de} \\
\text { alunos }\end{array}$ & $\begin{array}{l}\text { Não } \\
\text { Alfabético }\end{array}$ & Insuficiente & Razoável & Bom & Muito bom & $\begin{array}{l}\text { Total de } \\
\text { alunos }\end{array}$ \\
\hline $3^{\circ}$ anos & 43 & 2 & 5 & 8 & 23 & 5 & 43 \\
\hline $4^{\circ}$ anos & 31 & 1 & 5 & 11 & 10 & 4 & 31 \\
\hline $5^{\circ}$ ano & 36 & 4 & 8 & 17 & 5 & 2 & 36 \\
\hline TOTAL & 110 & 7 & 18 & 36 & 38 & 11 & 110 \\
\hline
\end{tabular}

Para que haja uma transformação verdadeira do ensino da leitura e da escrita, a escola precisa favorecer a aprendizagem significativa, abandonando as atividades mecânicas, e sem sentido, que levam 0 aluno a compreender a escrita como uma atividade pura e unicamente escolar. Para realmente transformar o ensino da leitura e da escrita na escola, é preciso, ainda, acabar com a discriminação que produz fracasso e abandono na escola, assegurando a todos o direito de 'se apropriar da leitura e da escrita como ferramentas essenciais de progresso cognoscitivo e de crescimento pessoal'.2

\section{Caracterização do produto/processo}

O Projeto de Leitura e Escrita atenderá aos alunos do $1^{\circ}$ ao $5^{\circ}$ ano, orientados pelos seus professores de classe, que por sua vez, uma vez por semana participarão de oficinas para a construção do material pedagógico adequado a faixa etária e dificuldades apresentadas durante o diagnóstico, anteriormente feitas.

Além de atender aos alunos da escola, o material produzido poderá circular nas famílias, ajudando assim a despertar nas outras crianças o gosto pela leitura através da prática da oratória (contando uma história ou parlenda, etc).

Atividades a serem realizadas

Oficinas: Sacolendas; Castelo (Conto de Fadas); Diário do Cachorrinho PUPY, O Papai Noel que gostava de Histórias;

Levantamento do material necessário para confecção do material pedagógico;

Modelação do material;

Recorte e montagem

Apresentação do material para o grupo de professores e as possibilidades das adaptações necessárias a faixa etária;

\section{Apresentação aos alunos:}

Cada professor apresentará o material a sua turma, assim distribuídos:

$1^{\circ}$ ano - Sacolendas

$2^{\circ}$ ano - Castelo

\footnotetext{
${ }^{2}$ Ler e escrever na escola: o real, o possível, o necessário - Cap.2 - Délia Lener.
} 
$3^{0}$ ano - Diário do Cachorrinho PUPY

$4^{0}$ e $5^{\circ}$ ano - $O$ Papai Noel que gostava de histórias!

Viabilidade e continuidade do projeto

0 projeto será desenvolvido ao longo do ano, durante pelo pelos 3 anos, sempre voltado ao objetivo da articulação dos saberes sociais com os comunicativos, estimulando e favorecendo a aprendizagem significativa.

\section{Estratégia de implementação}

\section{Análise SWOT}

Oportunidades:

Contribuir para a formação, crescimento intelectual e inclusão das crianças da comunidade e entorno;

Aperfeiçoar o processo de Alfabetização no Ciclo I;

Aprendizagem significativa, com responsabilidade, eficiente e prazerosa;

Formação de professores na escola;

Ameaças:

Mudanças políticas na pasta da Educação no Estado de São Paulo que interfiram nos projetos dentro da escola;

Demanda no Ciclo I;

\section{Forças:}

Grupo gestor articulado com as necessidades dos alunos;

Professores confiantes e empenhados no sucesso dos alunos;

Credibilidade da comunidade;

\section{Fraquezas:}

Discriminação em relação aos alunos com necessidades especiais

\section{Objetivos estratégicos}

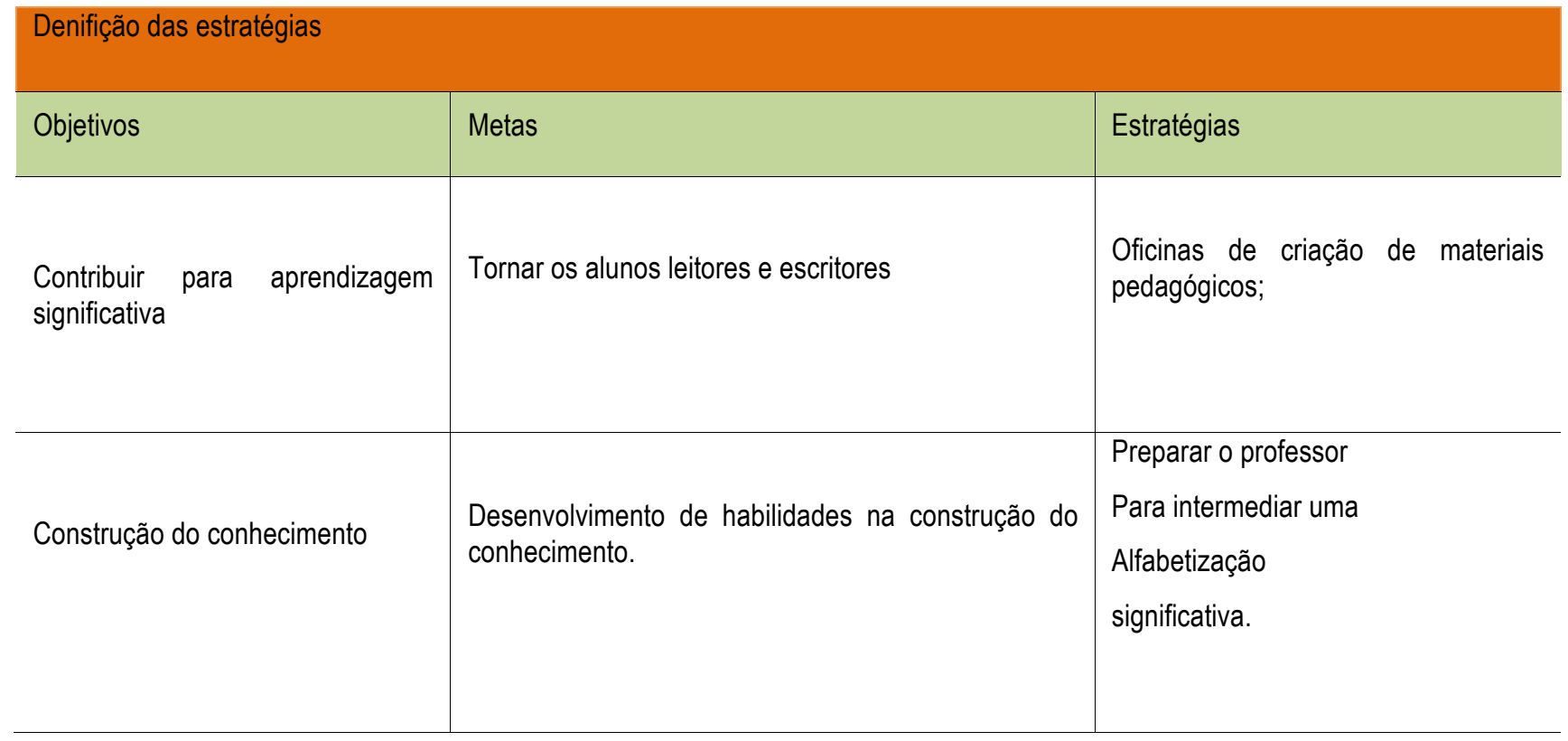




\begin{tabular}{|c|c|c|}
\hline \multicolumn{3}{|l|}{ Recursos necessários } \\
\hline O que vou precisar & Descrição & Como obter \\
\hline $\begin{array}{l}\text { Montagem de ambientes } \\
\text { alfabetizadores; } \\
\text { Cantinhos de leitura com o uso de } \\
\text { matérias pedagógicos } \\
\text { criados para esse fim }\end{array}$ & Aquisição de material pertinente ao projeto; & $\begin{array}{l}\text { Recursos obtidos via Edital Projetos } \\
\text { Inovadores em Educação, verba } \\
\text { prevista para despesas de capital. }\end{array}$ \\
\hline
\end{tabular}

\section{Marketing e comunicação}

O projeto será lançado na semana de Planejamento que ocorrerá no início do ano letivo de 2015 , onde 0 grupo gestor fará a apresentação aos professores, sendo iniciada neste momento a primeira das seis oficinas planejadas.

Toda equipe docente envolvida fará a difusão do projeto para seus pares e para os pais na $1^{\text {a }}$ Reunião de Pais, no início do ano letivo. Todos os materiais pedagógicos confeccionados serão expostos e poderão ser manipulados e/ou manuseados por toda a comunidade docente e discente, funcionários, visitantes e demais público.

Também deverá ser apresentado nas Orientações Técnicas promovidas pela Diretoria de Ensino Norte 2, na qual esta Unidade Escolar é jurisdicionada.

Assim torna-se necessário a seriedade e a crença que o Projeto atenda as expectativas de toda comunidade escolar que é uma aprendizagem significativa.

\section{Organização e gerência do empreendimento}

\section{Equipe Gestora}

A organização e gerência do empreendimento será executada pela equipe gestora da Unidade Escolar, que além de estar embuída da prática de projetos têm papel indispensável na promoção da leitura e escrita para as crianças.

\begin{tabular}{|c|c|c|c|}
\hline $\begin{array}{ll}\text { Membro } & \text { da } \\
\text { Equipe } & \end{array}$ & Função & Formação/Experiência & Atividades \\
\hline Marly Neves & Diretor de Escola & $\begin{array}{l}\text { Bióloga, Pedagoga, MBA Gestão } \\
\text { Empreendedora em Educação; } \\
\text { Professora aposentada da Instituição } \\
\text { Privada de Ensino; } \\
\text { Professora da Rede Estadual à } 20 \text { anos, } \\
6 \text { anos como Diretora de Escola; }\end{array}$ & $\begin{array}{l}\text { Organização de espaços para } \\
\text { oficinas e desenvolvimento do } \\
\text { projeto; } \\
\text { Levantamento de custos; } \\
\text { Aquisição de materiais; } \\
\text { Prestação de contas }\end{array}$ \\
\hline $\begin{array}{l}\text { Elisabeth Navarro } \\
\text { Gonçalves }\end{array}$ & Vice Diretor de Escola & $\begin{array}{l}\text { Professora Titular de Ciências da Rede } \\
\text { Municipal de Ensino de São Paulo, } \\
\text { Professora de Matemática da Rede } \\
\text { Estadual, Pedagoga. } \\
\text { Grande experiência com a execução de } \\
\text { Projetos; }\end{array}$ & $\begin{array}{l}\text { Supervisão das etapas do projeto; } \\
\text { Controle e distribuição de materiais; } \\
\text { Elaboração das pautas das } \\
\text { Reuniões com a equipe e com os } \\
\text { pais; }\end{array}$ \\
\hline
\end{tabular}




\begin{tabular}{|c|c|c|c|}
\hline $\begin{array}{l}\text { Maria da } \\
\text { Conceição de } \\
\text { Freitas Carneiro }\end{array}$ & $\begin{array}{l}\text { Professora } \\
\text { Coordenadora de Apoio } \\
\text { a Gestão Pedagógica }\end{array}$ & $\begin{array}{l}\text { Pedagoga; Formadora do Curso Letra e } \\
\text { Vida; Cursa Pacto Nacional para } \\
\text { Alfabetização; } 20 \text { anos de Experiência } \\
\text { como Professora Alfabetizadora; }\end{array}$ & $\begin{array}{l}\text { Orientação do planejamento do } \\
\text { professor; } \\
\text { Planejamento das etapas do } \\
\text { projeto; } \\
\text { Propor oficinas para confecção dos } \\
\text { materiais; }\end{array}$ \\
\hline $\begin{array}{l}\text { Tania de Almeida } \\
\text { Orlando }\end{array}$ & $\begin{array}{l}\text { Professora } \\
\text { Coordenadora } \\
\text { Pedagógica - Ciclo I }\end{array}$ & $\begin{array}{l}\text { Professora Titular de cargo na disciplina } \\
\text { de Arte; Pedagoga; Formadora do curso } \\
\text { Letra e Vida e EMAI (Educação } \\
\text { Matemática para os Anos Iniciais); } 15 \\
\text { anos de experiência em } \\
\text { desenvolvimentos de projetos }\end{array}$ & $\begin{array}{l}\text { Acompanhar todas as etapas do } \\
\text { projeto; } \\
\text { Discutir os possíveis entraves; } \\
\text { Propor ações para a execução do } \\
\text { projeto; } \\
\text { Orientações didáticas } \\
\text { acompanhamento das oficinas; }\end{array}$ \\
\hline
\end{tabular}

\section{Principais processos}

Para realizar o empreendimento é preciso contar com uma equipe de apoio que esta fora da sala de aula mas, que atuam diretamente no proesso de execução do projeto. A tabela a seguir, mostra o perfil desses colaboradores:

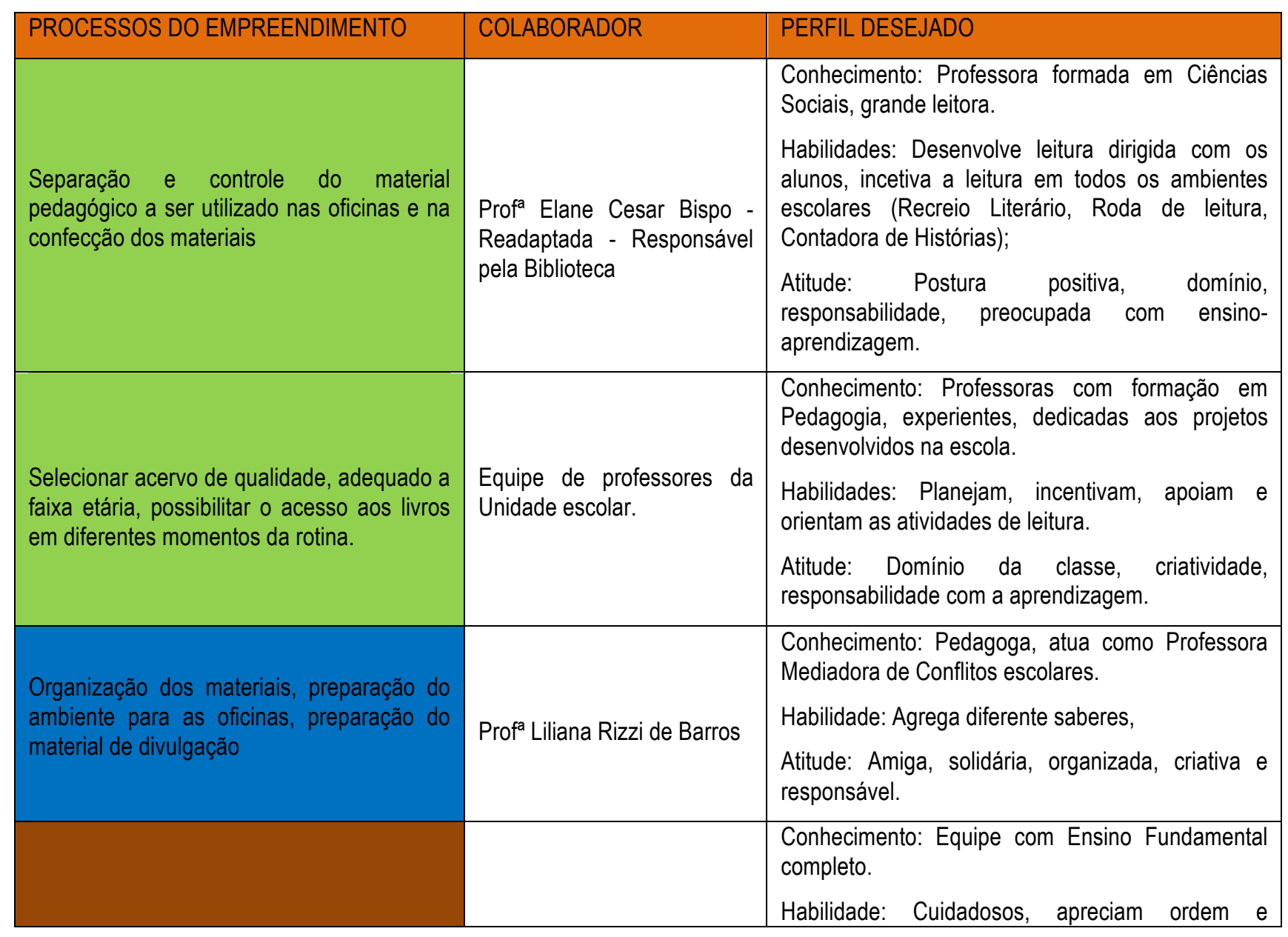




\section{Marly Neves}

\begin{tabular}{|l|l|l|}
$\begin{array}{l}\text { Limpeza e reorganização dos ambientes } \\
\text { escolares }\end{array}$ & $\begin{array}{l}\text { Elaine Cristina, Luana e Jose } \\
\text { Ricardo }\end{array}$ & $\begin{array}{l}\text { Atitude: Gosto pela organização e limpeza do } \\
\text { ambiente escolar e incentivam os alunos a } \\
\text { manterem ordem e limpeza para o bem estar de } \\
\text { todos. }\end{array}$ \\
\hline
\end{tabular}

\section{Legenda:}

\begin{tabular}{||l|l||}
\hline \hline & ProcessoPedagógico \\
\hline \hline & Processo Administrativo \\
\hline \hline & Processo de Apoio \\
\hline
\end{tabular}

\section{Plano financeiro}

\section{Investimento (despesa de capital)}

\begin{tabular}{|l|l|l|l|}
\hline Investimentos (despesas de capital) & \multicolumn{2}{l}{} \\
\hline Item & Ano1 & & \\
\hline Obras e infraestrutura & 0,00 & Ano2 & Ano3 \\
\hline Obras & 0,00 & 0,00 & 0,00 \\
\hline Instalações & 0,00 & 0,00 & 0,00 \\
\hline Material permanente & 0,00 & 0,00 & 0,00 \\
\hline Equipamentos & 0,00 & 0,00 & 0,00 \\
\hline Computadores & 0,00 & 0,00 & 0,00 \\
\hline Total & 0,00 & 0,00 & 0,00 \\
\hline
\end{tabular}

Não haverá despesas de capital pois a escola já conta com os equipamentos necessários para execução do Projeto. Obras e instalações só serão executadas pela Secretaria Estadual de Educação, quando aprovada pela FDE, e isso demanda muito tempo.

\section{Despesas Correntes}

\begin{tabular}{|l|l|l|l|}
\hline Projeção das Despesas Correntes & Total ANO 1 & Total ANO 2 & Total ANO 3 \\
\hline Material de Consumo & 28 & 29,96 & 32,06 \\
\hline Papel Sulfite - pc 500 fl. & 31,2 & 33,38 & 35,72 \\
\hline Cartolinas - pc 100 unidades & 10,9 & 11,66 & 12,48 \\
\hline Papel Cartão - pc 10 unidades & 47 & 50,29 & 53,81 \\
\hline Folha de EVA pc 10 unidades & 36 & 38,52 & 41,22 \\
\hline Cola de EVA - tubo $90 \mathrm{~g}$ & 32 & 34,24 & 36,64 \\
\hline Cola branca - 1kg & 150 & 160,5 & 171,73 \\
\hline Tesoura de uso geral - 1 unidades & 162 & 173,34 & 185,47 \\
\hline Tesoura escolar c/5 cortes- 1 unidades & 52,9 & 56,6 & 60,57 \\
\hline Tesoura de picotar - 1 unidade & & & \\
\hline
\end{tabular}


Leitura e Escrita: trabalhando com projetos no Ensino Fundamental

\begin{tabular}{|l|l|l|l|} 
Sacolas de papel Kraft pc 10 unidades & 4050 & 4333,5 & 4636,84 \\
\hline Fita velcro macho femea - rolo 25 mts & 350 & 374,5 & 400,72 \\
\hline Total & 4950 & 5296,49 & 5667,26 \\
\hline Passagens e Locomoção & Total ANO 1 & Total ANO 2 & Total ANO 3 \\
\hline & 0 & 0 & 0 \\
\hline Serviços de Terceiros & Total ANO 1 & Total ANO 2 & Total ANO 3 \\
\hline Oficineira & 1500 & 1500 & 1500 \\
\hline Total das Despesas Correntes & 6450 & 6796,40 & 7167,26 \\
\hline
\end{tabular}

\section{Despesas administrativas e de pessoal}

*Valor utilizado como contrapartida

\begin{tabular}{|c|c|c|c|}
\hline Administrativas & Total ANO 1 & Total ANO 2 & Total ANO 3 \\
\hline Energia Elétrica & 300 & 300 & 300 \\
\hline Água & 720 & 720 & 720 \\
\hline Total & 1020 & 1020 & 1020 \\
\hline Pessoal & \begin{tabular}{|l|} 
Total ANO 1 \\
\end{tabular} & Total ANO 2 & \begin{tabular}{|l|} 
Total ANO 3 \\
\end{tabular} \\
\hline Professora Auxiliar & 2400 & 2400 & 2400 \\
\hline Total & 2400 & 2400 & 2400 \\
\hline Total das Despesas Adm+Pessoal & 3420 & 3420 & 3420 \\
\hline
\end{tabular}

\section{Necessidades de recursos}

\begin{tabular}{|c|c|c|c|c|}
\hline \multicolumn{4}{|l|}{ Cálculo da Necessidade de Recursos } & \multirow[b]{2}{*}{ TOTAL } \\
\hline Item & ANO 1 & ANO 2 & ANO 3 & \\
\hline I. Total das Despesas Correntes & $6.450,00$ & $6.796,50$ & $7.167,26$ & $20.413,76$ \\
\hline Material de Consumo & $4.950,00$ & $5.296,50$ & $5.667,26$ & $15.913,76$ \\
\hline Passagens e Despesas com Locomoção & 0,00 & 0,00 & 0,00 & 0,00 \\
\hline Serviços de Terceiros & $1.500,00$ & $1.500,00$ & $1.500,00$ & $4.500,00$ \\
\hline II. Total de Despesas Administrativas & $1.020,00$ & $1.020,00$ & $1.020,00$ & $3.060,00$ \\
\hline III. Total de Despesas com Pessoal & $2.400,00$ & $2.400,00$ & $2.400,00$ & $7.200,00$ \\
\hline IV. Total de Despesas de Capital (investimentos) & 0,00 & 0,00 & 0,00 & 0,00 \\
\hline Necessidade de Recursos (I+|I+|II+IV) & $9.870,00$ & $10.216,50$ & $10.587,26$ & $30.673,76$ \\
\hline Recursos Edital & $6.450,00$ & $6.796,50$ & $7.167,26$ & $20.413,76$ \\
\hline Recursos da Organização (contrapartida) & $3.420,00$ & $3.420,00$ & $3.420,00$ & $10.260,00$ \\
\hline
\end{tabular}




\section{Marly Neves}

\section{Validações}

\begin{tabular}{|c|c|c|c|}
\hline Itens Financiáveis & Valores Consolidados & $\%$ & Validação \\
\hline Despesas Correntes & $20.413,75$ & $50 \%$ & - \\
\hline Despesas de Capital(máximo 50\% do projeto) & 0 & $0 \%$ & ok:0\% \\
\hline Total de Recursos Solicitados & $20.413,76$ & $100 \%$ & ok:<100mil \\
\hline
\end{tabular}

\begin{tabular}{|l|l|}
\hline Contrapartida & $10.260,00$ \\
\hline Valor total da contrapartida & $20.413,76$ \\
\hline Valor solicitado ao edital do projeto & $50,26 \%$ \\
\hline Percentual: contrapartida/recursos solicitados &
\end{tabular}

\section{Anexos: Fotos e Pôster}

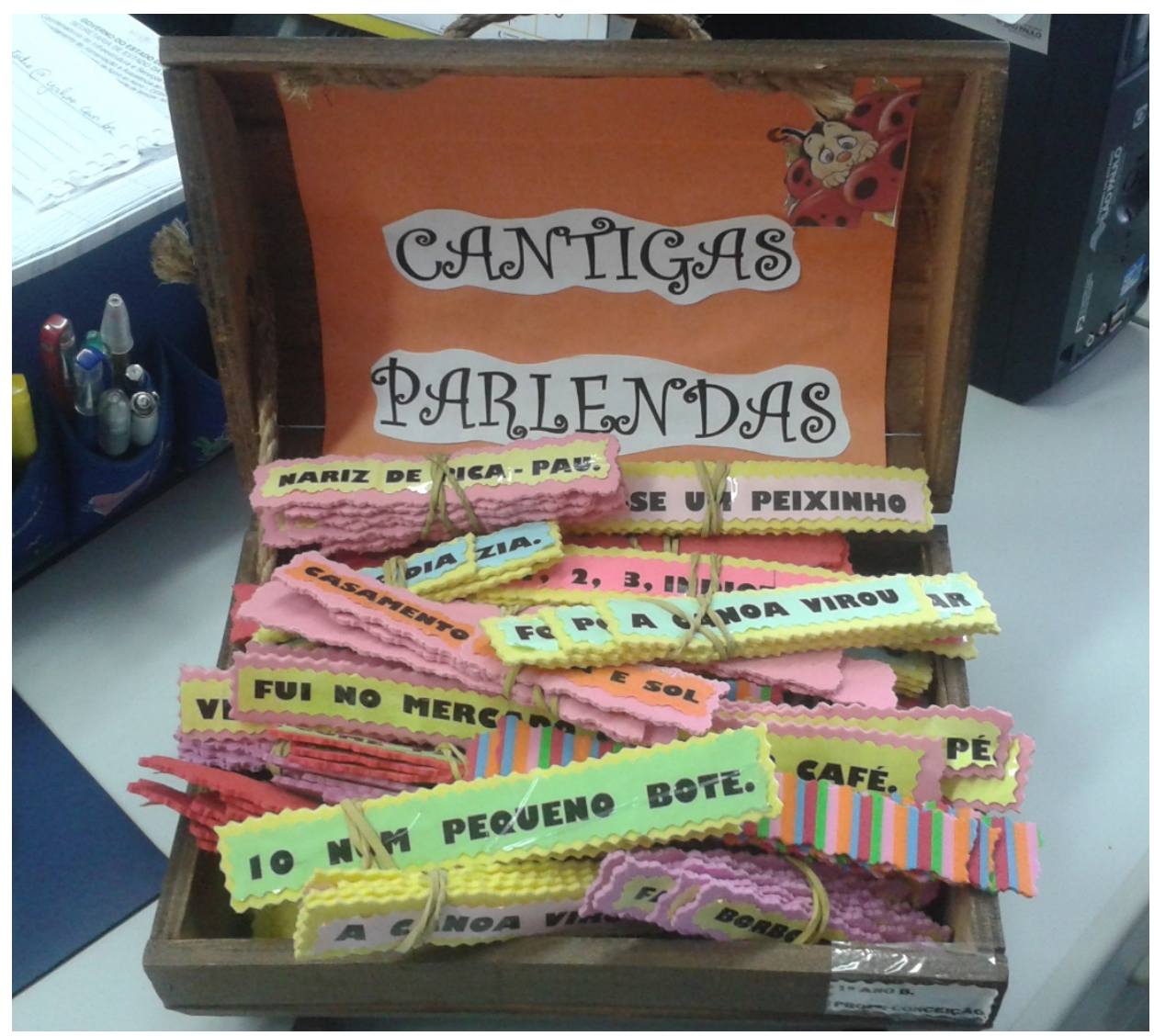



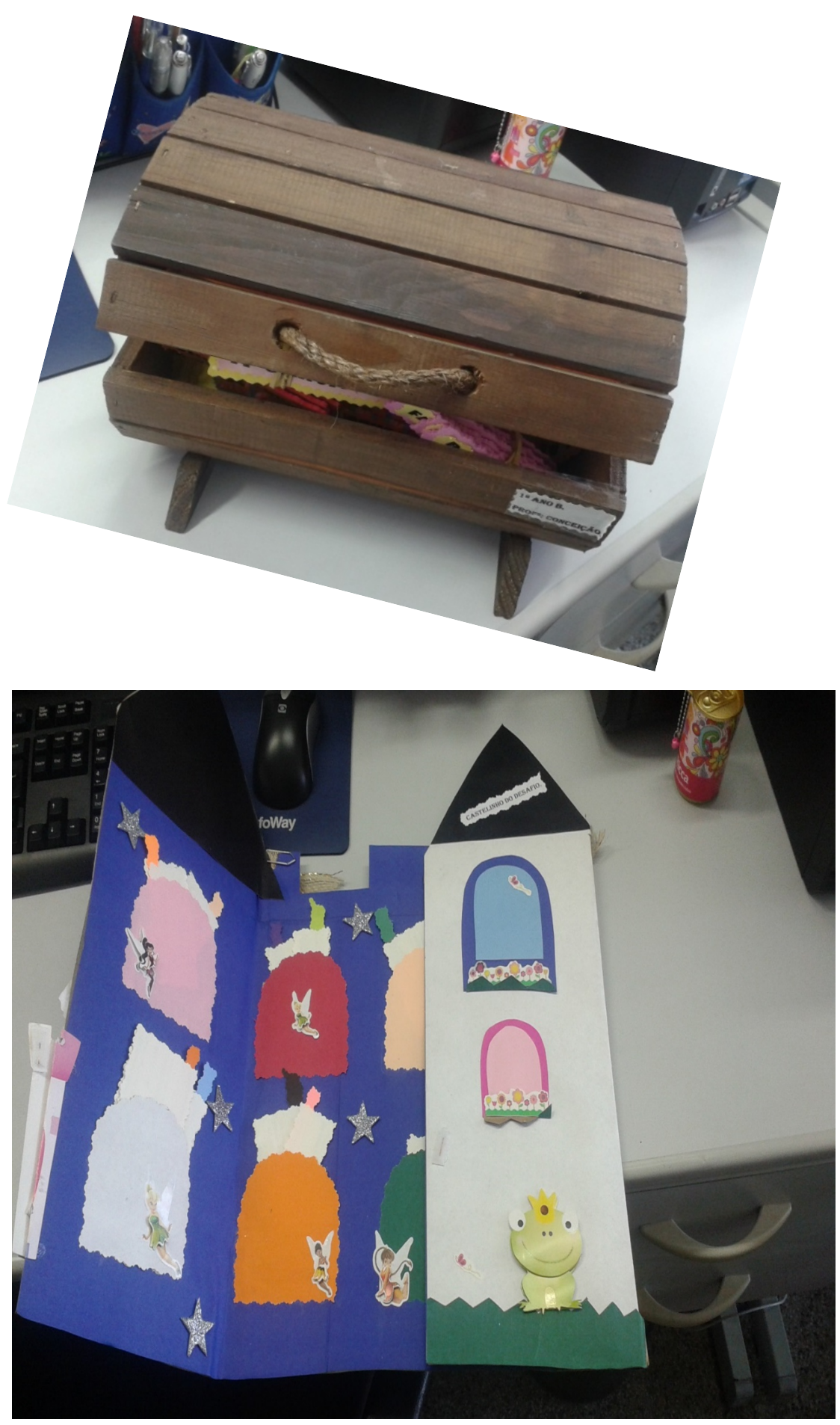

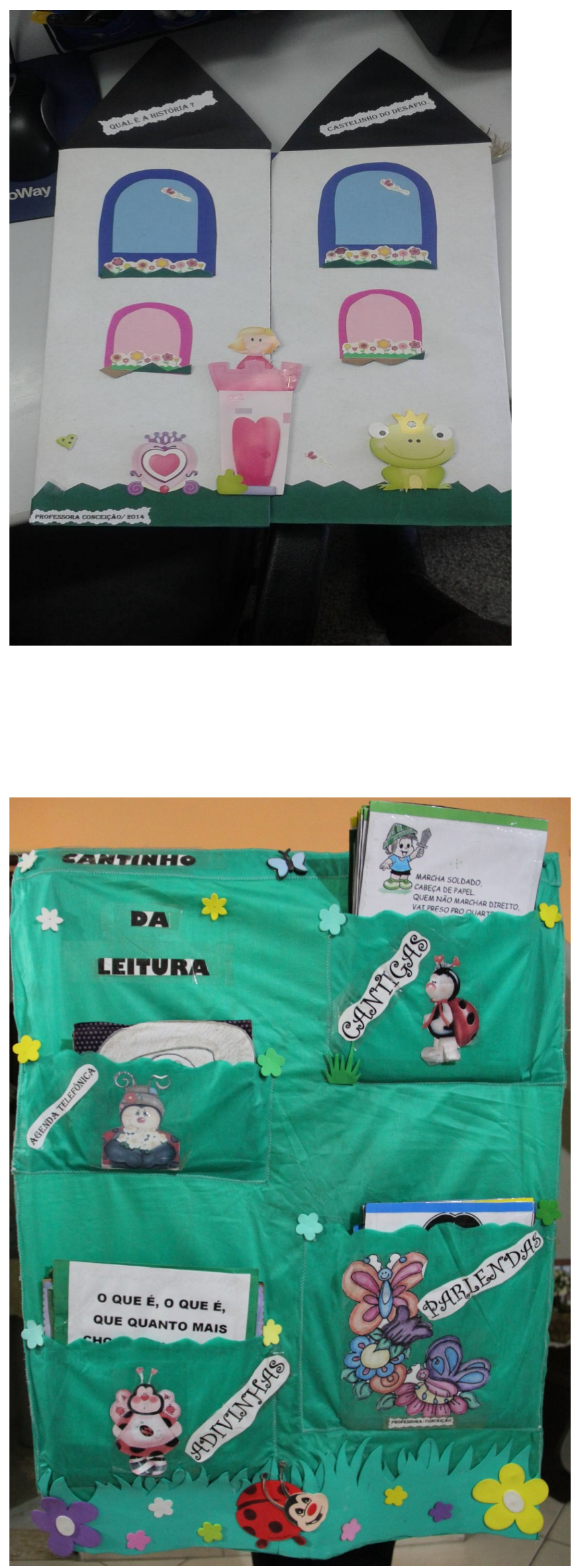

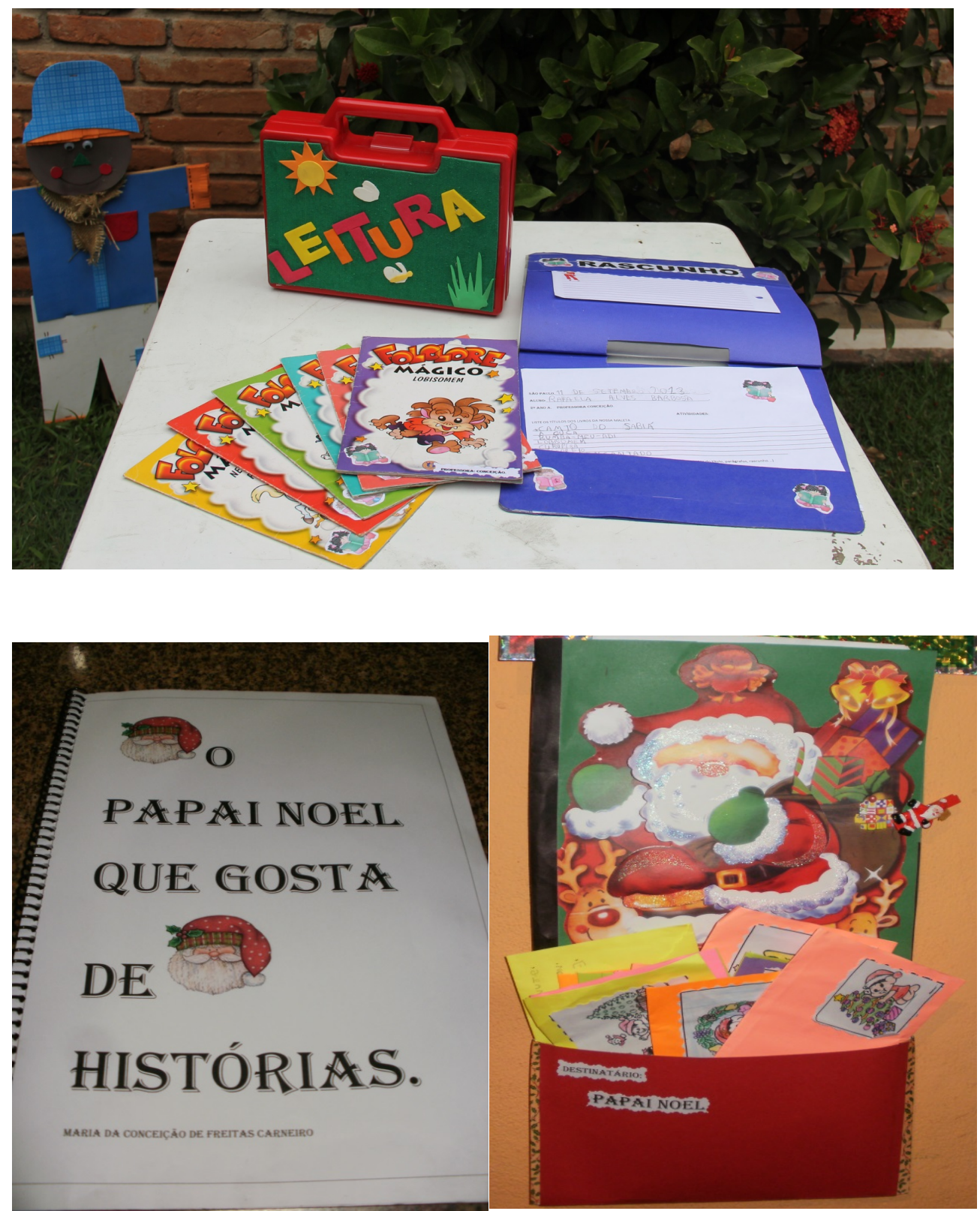


\section{Marly Neves}

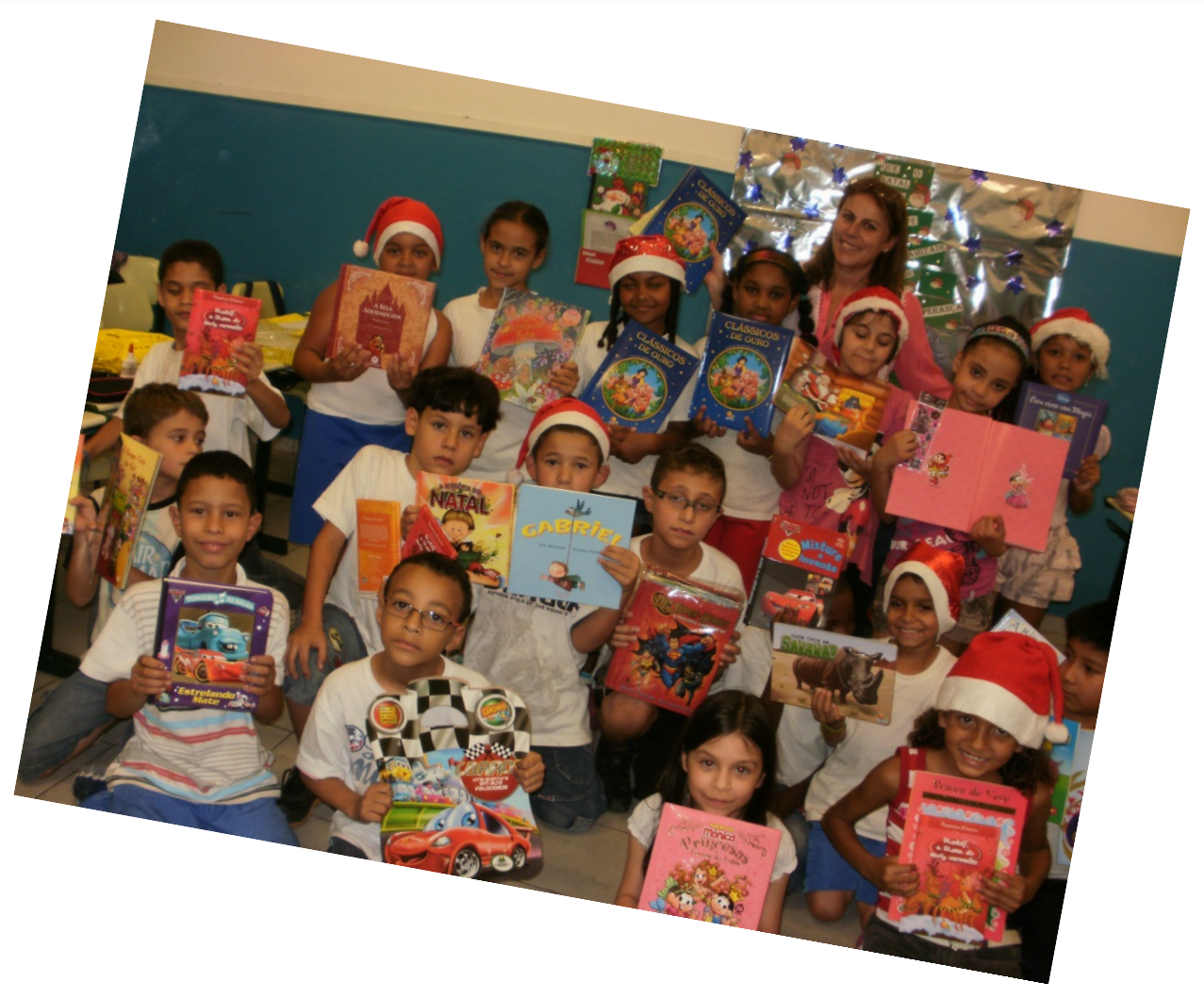

